\title{
Structural, Electrical and Dielectric Properties of Dodecylbenzene Sulphonic Acid Doped Polypyrrole/Nano- $\mathrm{Y}_{2} \mathrm{O}_{3}$ Composites
}

\author{
Muhammad $\operatorname{Irfan}^{1} \cdot$ Abdul Shakoor ${ }^{1}$
}

Received: 20 May 2019 / Accepted: 16 August 2019 / Published online: 24 August 2019

(c) The Author(s) 2019

\begin{abstract}
We report a facile strategy to synthesized the PPy-DBSA- $\mathrm{Y}_{2} \mathrm{O}_{3}$ composites with increasing amount of $\mathrm{Y}_{2} \mathrm{O}_{3}(2 \%, 4 \%$ and $8 \%)$ by in situ polymerization method. The samples were characterized by XRD, FTIR, SEM and dielectric spectroscopy. Structural and morphological analysis reveals the conformation of composite formation, increase in crystallinity and particle size also increased by doping $\mathrm{Y}_{2} \mathrm{O}_{3}$ into PPy-DBSA matrix. The frequency dependent AC conductivity $\left(\sigma_{\mathrm{ac}}\right)$, dielectric constant $\left(\varepsilon^{\prime}\right)$ and loss factor $\left(\varepsilon^{\prime \prime}\right)$ were measured in the frequency range from $20 \mathrm{~Hz}$ to $1 \mathrm{MHz}$. All measured quantities; $\sigma_{\mathrm{ac}}, \varepsilon^{\prime}$ and $\varepsilon^{\prime \prime}$ are enhanced with increase in $\mathrm{Y}_{2} \mathrm{O}_{3}$ content in the composites at all frequencies. Dielectric constant value for all samples is very high at low frequency however decreases with increase in frequency. Synthesis of PPy-DBSA-Y $\mathrm{O}_{3}$ composite materials with a large dielectric constant is very important for the improvement of electronic devices applications.
\end{abstract}

Keywords AC conductivity $\cdot$ Dielectric constant $\cdot$ Dielectric loss $\cdot \mathrm{XRD} \cdot \mathrm{Nano}-\mathrm{Y}_{2} \mathrm{O}_{3}$

\section{Introduction}

Intrinsically conducting polymers (ICPs) have significant applications in electromagnetic shielding, electrical displays, rechargeable batteries, optical computers and molecular electronics, several types of sensors and actuators, smart structures in electronic devices, drug release systems, synthetic nerves and inducting exchange membranes [1-4]. One of the outstanding features of ICPs is that it is promising to control conductivity of these polymers over extensive range from insulating to metallic by proper doping, addition of fillers and by intercalating these polymers into different inorganic host materials such as $\mathrm{TiO}_{2}$ [5], $\mathrm{TaS}_{2}$ [6], $\mathrm{CdPS}_{3}$ [7], $\mathrm{V}_{2} \mathrm{O}_{5}$ [8] and $\mathrm{Y}_{2} \mathrm{O}_{3}$ [9]. Intercalation of conducting polymers in the interlameller galleries of nano- $\mathrm{Y}_{2} \mathrm{O}_{3}$ clay has been explored by several researchers [10]. Clay based polymer composites have been focus of a large number of investigations during the past two decades because of their numerous engineering applications. These composites show better mechanical and thermal properties, cheap permeability for gases and flame retardant and fire dowsing characteristics

Muhammad Irfan

mirfanphysics@gmail.com

1 Department of Physics, Bahauddin Zakariya University, Multan 60800, Pakistan
$[4,11,12]$. Intercalation of polymer into the clay galleries and exfoliation of nanostructured clay platelets in the polymer matrix provide exclusive combination of organic and inorganic components at molecular level which communicates synergistic properties to conducting polymer clay composites which cannot be achieved from individual components, such as enhanced and well-disciplined electrical conductivity [13], improved thermal stability and outstanding mechanical, barrier and anticorrosive properties [14, 15]. Composites of conducting polymers and nanostructured clays were used as conductive fillers in insulating polymer exhibits the increase in electrical conductivity and low percolation threshold [16] as compare with pure conducting polymer. Among several conducting polymers, polypyrrole (PPy) is one of the most studied conducting polymer, due to environmental stability, low cost, ease of synthesis and controlling their electrical properties [17]. PPy and its derivatives have been successfully employed in electronic devices as hole and electron transport semiconducting materials in transistors and LEDs $[18,19]$. In the existing work, to understand the mechanism of conduction and dielectric properties may be valuable in developing the device performance and designing the electronic devices. The survey of literature reveals that the detailed conductivity/dielectric studies on PPy-DBSA- $\mathrm{Y}_{2} \mathrm{O}_{3}$ composites are scarce. Herein, we report the PPy-DBSA- $\mathrm{Y}_{2} \mathrm{O}_{3}$ composites prepared by in situ 
polymerization method and characterized these samples by XRD, FTIR, SEM and dielectric spectroscopy.

\section{Experimental Details}

The Pyrrole (Fluka) was refined under reduce pressure also stored at low temperature before to use. Ammonium persulphate (APS), dodecylbenzene sulfonic acid (DBSA) and yttrium oxide $\left(\mathrm{Y}_{2} \mathrm{O}_{3}\right)$ were achieved from Sigma-Aldrich and used as obtained. The all materials were used as presented without any more purification.

\subsection{Preparation of Polypyrrole (PPy)}

The required amount of APS was isolated in $100 \mathrm{~mL}$ of deionized water and stirred for $1 \mathrm{~h}$ and then pyrrole was dissolved regularly within the suspension throughout the stirring at $5{ }^{\circ} \mathrm{C}$. The monomer to oxidant molar ratio was kept $1: 1$. The suspension was left for 1 day for polymerization. Finally, the suspension was filtered and cleaned with deionized water until the filtrate turns to colorless. The greenish black paste of PPy was achieved which was desiccated at $60^{\circ} \mathrm{C}$ in vacuum oven for 1 day.

\subsection{Preparation of PPy-DBSA- $\mathrm{Y}_{2} \mathrm{O}_{3}$ Composite}

The $0.15 \mathrm{~mol}$ of DBSA was dissolved in $100 \mathrm{~mL}$ of deionized water, $0.3 \mathrm{~mol}$ of Pyrrole was put in gradually in the mixture solution which was retained on magnetic stirring. 30\% hydrochloric acid $(\mathrm{HCl})$ was introduced into the reaction mixture to keep $\mathrm{pH}$ value 0 and 1 with strong magnetic stirring. To this solution, $\mathrm{Y}_{2} \mathrm{O}_{3}$ powder was dissolved into the polymerization mixture under stirring. After $1 \mathrm{~h}$, the proper amount of APS was dissolved in $100 \mathrm{~mL}$ of de-ionized water drop wise under strong stirring for half hour period. The monomer/oxidant/dopant molar ratio was taken $1: 1: 1 / 4$. Then, $1 \mathrm{~L}$ methanol was also incorporated into the mixture and kept it at room temperature for 2 days to attain complete polymerization. After all, the suspension was filtered and cleaned with de-ionized water up to filtrate changes to colorless. The greenish black paste of PPy-DBSA- $\mathrm{Y}_{2} \mathrm{O}_{3}$ was conquered which was desiccated at $60{ }^{\circ} \mathrm{C}$ in vacuum oven for 1 day.

\subsection{Measurements}

X-ray powder diffraction analysis was carried out employing automated diffractometer, Panalytical X'Pert PRO equipped with $\mathrm{CuK} \alpha$ radiations $(\lambda=1.54 \AA$ ). The Fourier transform infrared spectra was recorded on $\mathrm{KBr}$ pellet samples in the range of $4000-500 \mathrm{~cm}^{-1}$ by using a Perkin-Elmer Fourier transforms infra-red spectrometer. Scanning electron microscopy was carried out on an EVO50 ZEISS instrument. Dielectric and Conductivity were measured of pressed pellets by applying 10 ton pressure in stainless steel die of 4-mm in diameter and 1-mm thickness in press machine by using a two point technique in the frequency range $20 \mathrm{~Hz}$ to $1 \mathrm{MHz}$. The samples were connected to a Keithley 2400 electrometers and a current source electrometer.

\section{Results and Discussion}

\subsection{Structural Analysis}

The X-ray diffraction pattern for polypyrrole (PPy), PPy-DBSA and their composite of PPy-DBSA- $\mathrm{Y}_{2} \mathrm{O}_{3}$ are revealed in Fig. 1. Figure 1d shows the main crystalline peaks of $\mathrm{Y}_{2} \mathrm{O}_{3}$ nanoparticles observed at $2 \theta=29.46^{\circ}$, $34.12^{\circ}, 48.73^{\circ}$ and $57.90^{\circ}$ corresponds to periodicity $\mathrm{d}=0.16,0.14,0.10$ and $0.91 \mathrm{~nm}$ in the direction of (222), (400), (440) and (622) planes is in good agreement with that on the JCPD card S25-1200, which describes that the sample has cubic crystal system taking space group I213. Adopting Scherer's formula [20, 21], the calculated crystalline size of $\mathrm{Y}_{2} \mathrm{O}_{3}$ was found to be $95 \mathrm{~nm}$. From X-ray diffraction intensity versus $2 \theta$, it is explored that the XRD pattern of pristine PPy indicates no sharp peak except a broad peak at $2 \theta=22^{\circ}-28^{\circ}$ (Fig. 1a) which is typical peak of PPy and suggests that the nature of PPy is amorphous has been reported [22]. The XRD pattern for PPyDBSA also amorphous exposed in the range of $20^{\circ}-30^{\circ}$ in Fig. 1b. As in the XRD pattern of PPy-DBSA- $\mathrm{Y}_{2} \mathrm{O}_{3}$ composite (Fig. 1c) was shifted towards higher angle due

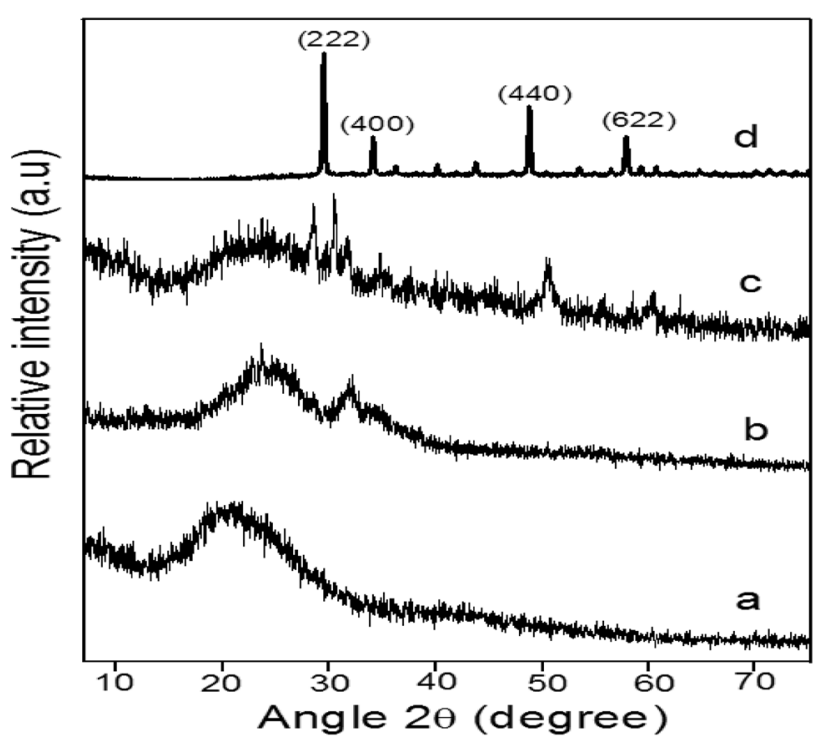

Fig. 1 XRD pattern of (a) PPy, (b) PPy-DBSA, (c) PPy-DBSA- $\mathrm{Y}_{2} \mathrm{O}_{3}$ (d) pure $\mathrm{Y}_{2} \mathrm{O}_{3}$ 
to the intercalation of PPy and $\mathrm{Y}_{2} \mathrm{O}_{3}$ nanoparticles during the process of synthesis. Consequently, $\mathrm{d}$-values are calculated experimentally via employing Bragg's relation [23]. In Fig. 1c three sharp crystalline peaks of PPy-DBSA$\mathrm{Y}_{2} \mathrm{O}_{3}$ at $2 \theta=30.42,50.68$ and $60.64^{\circ}$ resembles with value of $\mathrm{d}=0.15,0.99$ and $0.088 \mathrm{~nm}$ are reduce in composite due to the presence of $\mathrm{Y}_{2} \mathrm{O}_{3}$ was also observed. Hence, these sharp peaks are openly exhibiting that after mixing $\mathrm{Y}_{2} \mathrm{O}_{3}$ into the PPy-DBSA crystallinity is enhanced [24].

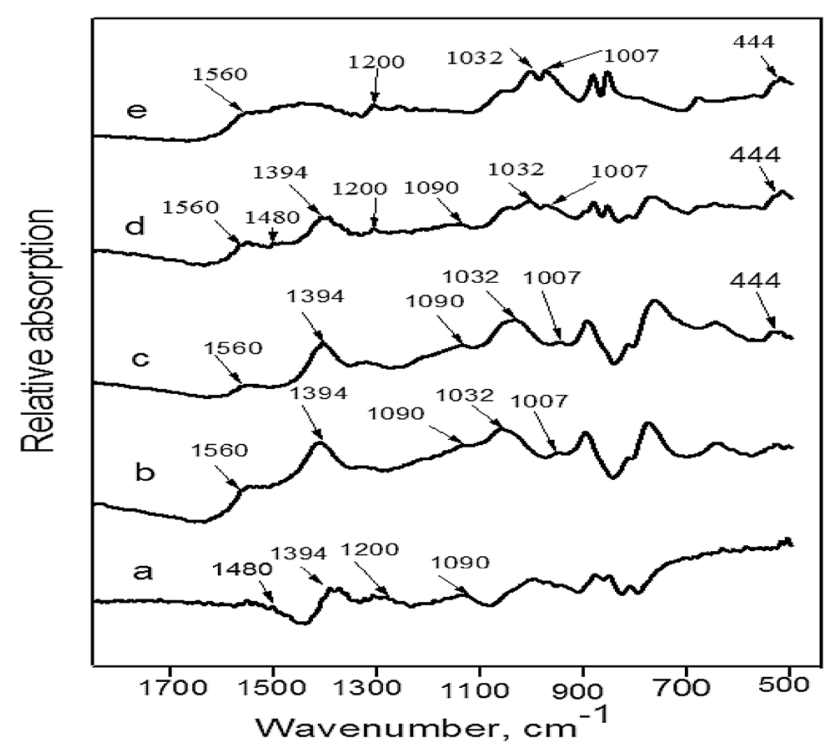

Fig. 2 FTIR spectra of (a) pure PPy (b) PPy-DBSA (c) $2 \% \mathrm{Y}_{2} \mathrm{O}_{3}$ (d) $4 \% \mathrm{Y}_{2} \mathrm{O}_{3}$ and (e) $8 \%$ of $\mathrm{Y}_{2} \mathrm{O}_{3}$ in PPy-DBSA

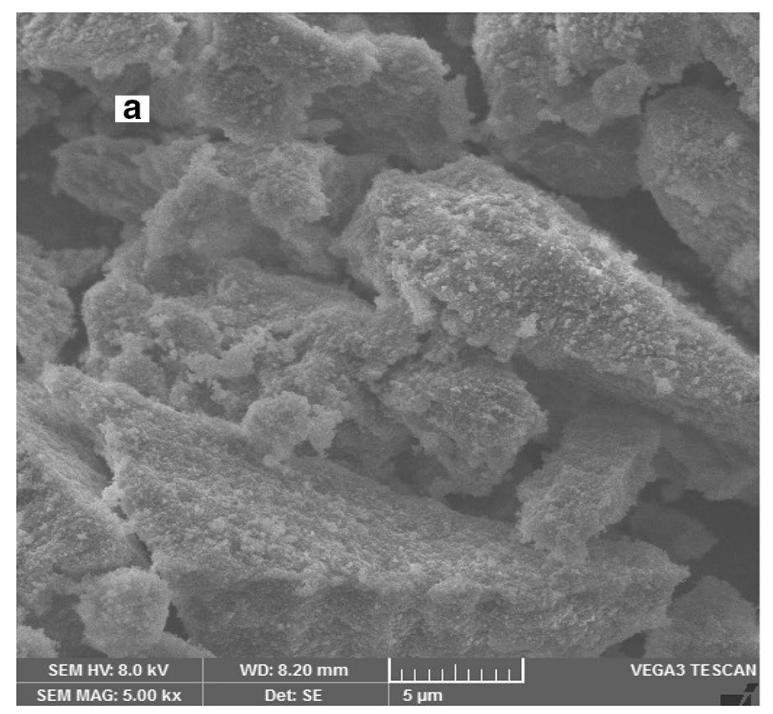

\subsection{FTIR Spectra}

FTIR spectra in absorption mode of pure polypyrrole (PPy), PPy-DBSA and composites of PPy-DBSA- $\mathrm{Y}_{2} \mathrm{O}_{3}$ are publicized in Fig. 2 (curve a-e). The FTIR spectra of PPy and PPy-DBSA (Fig. 2a-b) peak at $1090 \mathrm{~cm}^{-1}$ relates to symmetric $\mathrm{C}-\mathrm{H}$ in the plane mode. The peak at $1200 \mathrm{~cm}^{-1}$ is $\mathrm{N}-\mathrm{H}$ in the plane mode and it was typical absorption peak for PPy. The stretching modes of PPy are established in the region $1600-1400 \mathrm{~cm}^{-1}$. The peak at $1550 \mathrm{~cm}^{-1}$ can be assigned for $\mathrm{C}-\mathrm{C}$ stretching mode of PPy chains [25]. The $\mathrm{C}=\mathrm{C}$ stretching vibrations at 1560 and $1480 \mathrm{~cm}^{-1}, \mathrm{C}-\mathrm{N}$ and $\mathrm{C}-\mathrm{C}$ vibrations at $1394 \mathrm{~cm}^{-1}$ and $\mathrm{C}-\mathrm{H}$ out of plane twisted vibration of PPy of polymer chain [26, 27]. Two other peaks of $\mathrm{SO}_{3}$ near 1032 and $1007 \mathrm{~cm}^{-1}$ are identified in doped PPy which are characteristic peaks of sulphonic group [28, 29]. Figure 2c-e demonstrates the FTIR spectra of PPy-DBSA$\mathrm{Y}_{2} \mathrm{O}_{3}$ composites which show absorption peaks at 1554 and $1460 \mathrm{~cm}^{-1}$ are the individual pyrrole ring vibration furthermore, the peak of metal oxide was observed at $444 \mathrm{~cm}^{-1}$. Thus, these shifts in the peaks in the PPy-DBSA- $\mathrm{Y}_{2} \mathrm{O}_{3}$ samples show that interfacial interaction exists between the two components.

\subsection{Scanning Electron Microscopy}

The surface morphology of the samples was investigated by means of Scanning electron microscopy analysis. The SEM micrograph of pure $\mathrm{Y}_{2} \mathrm{O}_{3}$ nanoparticles and PPyDBSA- $\mathrm{Y}_{2} \mathrm{O}_{3}$ composite can be attained and are shown in Fig. 3a and b. In order to substantiate the crystallinity of conducting polypyrrole (PPy) doped with dodecylbenzene sulfonic acid (DBSA) along with yttrium oxide $\left(\mathrm{Y}_{2} \mathrm{O}_{3}\right)$

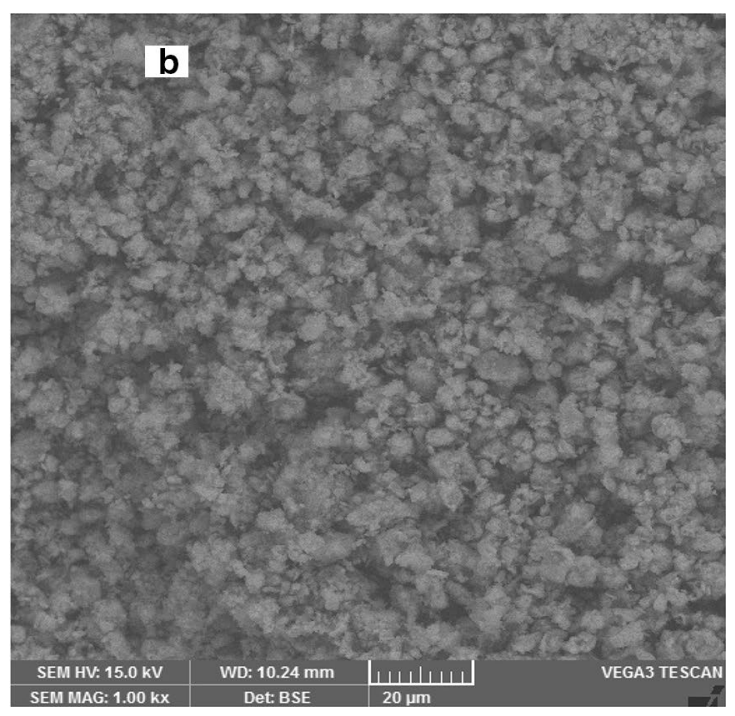

Fig. 3 SEM images of a Pure $\mathrm{Y}_{2} \mathrm{O}_{3}$ and b PPy-DBSA-8\% $\mathrm{Y}_{2} \mathrm{O}_{3}$ composite 
nanoparticles. Micrograph of pristine polypyrrole show bright granular agglomerates and platelet structure of pure yttrium oxide, however, the particle size of doped polypyrrole enhanced moreover the structure is flakier. From this, it may be concluded that the composite of PPy-DBSA$\mathrm{Y}_{2} \mathrm{O}_{3}$ is exhibiting enlargement in particle size moreover a dual structure of platelet in addition to flakier.

\subsection{Frequency Dependence of Dielectric Behavior}

\subsubsection{Dielectric Constant $\left(\varepsilon^{\prime}\right)$}

The variation of $\varepsilon^{\prime}$ versus frequency ( $20 \mathrm{~Hz}$ to $1 \mathrm{MHz}$ ) for PPy, PPy-DBSA along with PPy-DBSA- $\mathrm{Y}_{2} \mathrm{O}_{3}$ composites with different weight percentage of $\mathrm{Y}_{2} \mathrm{O}_{3}(2 \%, 4 \%$ and $8 \%)$ at room temperature is plotted in Fig. 4. The $\varepsilon^{\prime}$ for all samples varies nonlinearly as function of frequency up to $1 \mathrm{MHz}$. A decrease in $\varepsilon^{\prime}$ was observed by increasing the frequency and it is nearly constant at higher frequencies. At low frequency region dielectric distribution is observed but it becomes nearly independent at high frequency region. Further, we have observed that the values of $\varepsilon^{\prime}$ for these composites are reduces by increasing the weight percentage of $\mathrm{Y}_{2} \mathrm{O}_{3}$. This can be attributed that the dipoles moving smaller distance within the polymeric chains in the direction of applied field. Conversely, a high value of $\varepsilon^{\prime}$ was observed experimentally at low frequency region due to polarization as well as hopping of charge carriers (polarons and bipolarons) between the localized sites in the system.

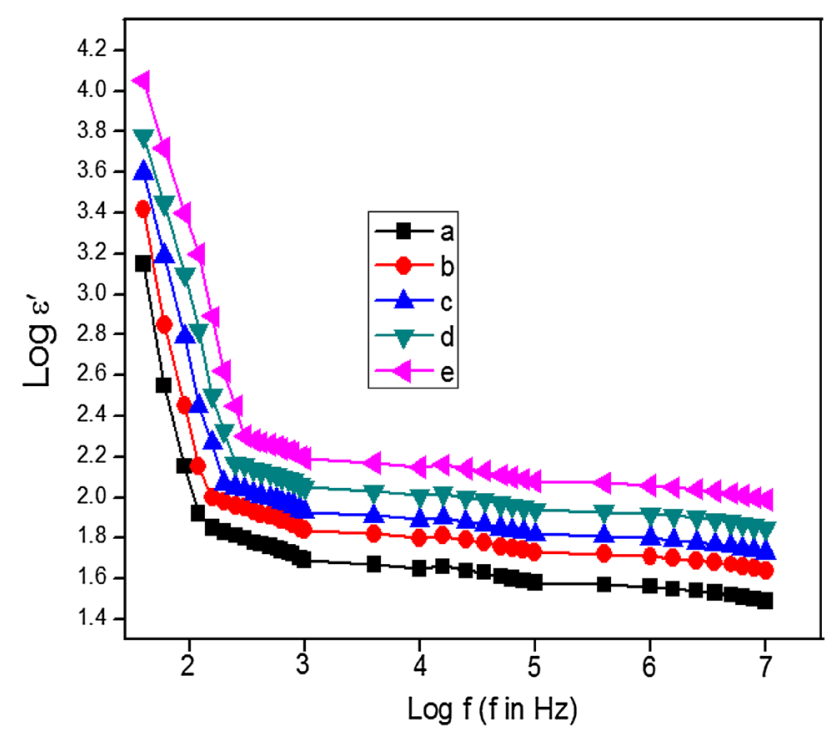

Fig. 4 Variation of dielectric constant vs frequency for (a) PPy (b) PPy-DBSA (c) $2 \% \mathrm{Y}_{2} \mathrm{O}_{3}$, (d) $4 \% \mathrm{Y}_{2} \mathrm{O}_{3}$, (e) $8 \%$ of $\mathrm{Y}_{2} \mathrm{O}_{3}$ in PPy-DBSA

\subsubsection{Dielectric Loss $\left(\varepsilon^{\prime \prime}\right)$}

The variation of $\varepsilon^{\prime \prime}$ versus frequency ( $20 \mathrm{~Hz}$ to $1 \mathrm{MHz}$ ) for PPy, PPy-DBSA and PPy-DBSA- $\mathrm{Y}_{2} \mathrm{O}_{3}$ composites with increasing weight percentage of $\mathrm{Y}_{2} \mathrm{O}_{3}$ at room temperature is exposed in Fig. 5. The $\varepsilon^{\prime \prime}$ for all samples reduces at low frequency region but it remains constant at higher frequencies. The $\varepsilon^{\prime \prime}$ was found to be decreases by increasing the frequency as well as it shows that the amount of energy disintegrates in dielectric with applied field. At low frequency region, the presence of insulating grain boundaries and large value of resistivity so required more energy for the hopping of charge carriers between the localized sites. Hence, we observed low value of $\varepsilon^{\prime \prime}$ at high frequency region because conducting grains present minimum resistance by increasing the weight percentage of $\mathrm{Y}_{2} \mathrm{O}_{3}$.

\subsection{Frequency Dependence of AC Conductivity}

The variation in AC conductivity $\left(\sigma_{\mathrm{ac}}\right)$ versus frequency ranging from $20 \mathrm{~Hz}$ to $1 \mathrm{MHz}$ for PPy, PPy-DBSA and PPyDBSA- $\mathrm{Y}_{2} \mathrm{O}_{3}$ composites at room temperature is presented in Fig. 6. Pristine PPy and all the composites show frequency independent $\mathrm{AC}$ conductivity at low frequency region and followed high frequency dispersive region where AC conductivity depends upon the frequency and follow a fractional power law. This universal behavior was observed in a present study of synthesized PPy-DBSA- $\mathrm{Y}_{2} \mathrm{O}_{3}$ composites. The real part of the electrical conductivity $\sigma(\omega)$ can be expressed as:

$\sigma(\omega)=\sigma_{0}+\mathrm{A} \omega^{\mathrm{n}}$

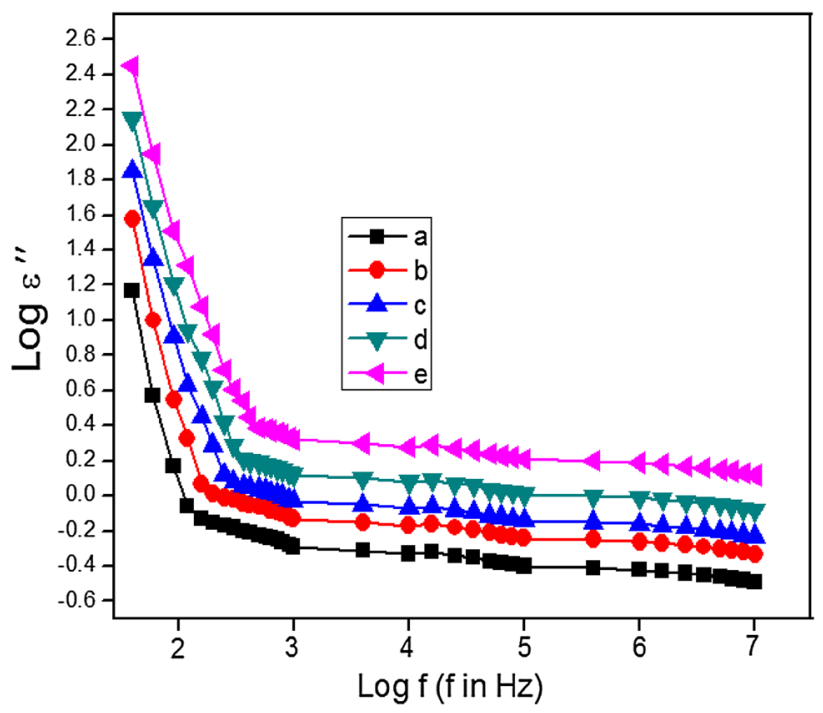

Fig. 5 Variation of dielectric loss vs frequency for (a) PPy (b) PPyDBSA (c) $2 \% \mathrm{Y}_{2} \mathrm{O}_{3}$, (d) $4 \% \mathrm{Y}_{2} \mathrm{O}_{3}$, (e) $8 \%$ of $\mathrm{Y}_{2} \mathrm{O}_{3}$ in PPy-DBSA 


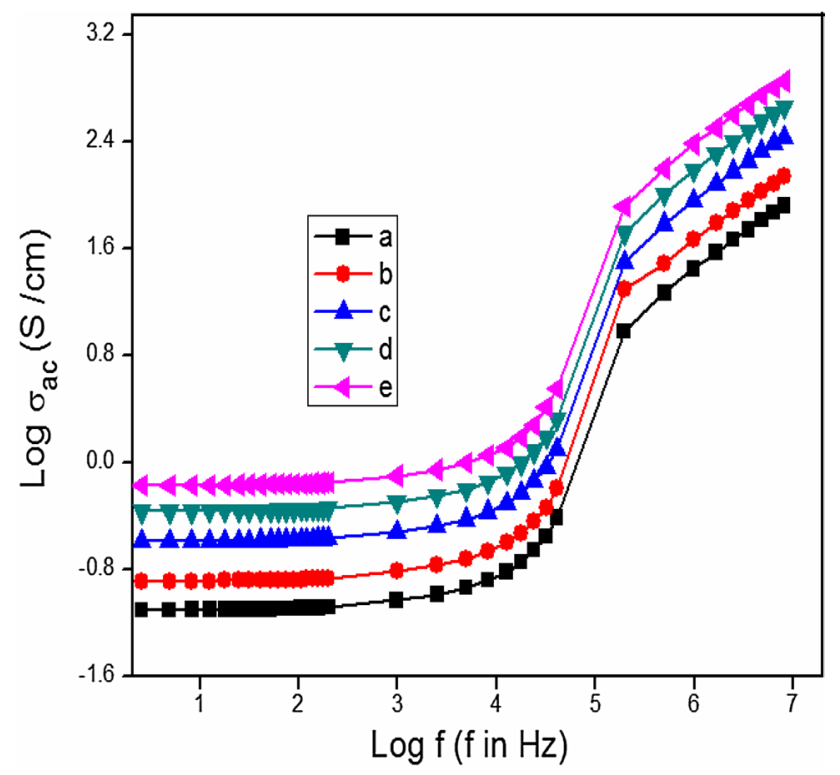

Fig. 6 Variation of AC conductivity vs frequency for (a) PPy, (b) PPy-DBSA (c) $2 \% \mathrm{Y}_{2} \mathrm{O}_{3}$ (d) $4 \% \mathrm{Y}_{2} \mathrm{O}_{3}$ (e) $8 \%$ of $\mathrm{Y}_{2} \mathrm{O}_{3}$ in PPy-DBSA

where $\sigma_{0}$ stands for dc conductivity, "A" pre-exponential factor with units of electrical conductivity, " $\omega$ " angular frequency of applied field and " $n$ " is fractional exponent a dimensionless factor. DC conductivity becomes independent of frequency as $\mathrm{n}$ approaches to zero, when $\mathrm{n} \leq 1$, electrical conductivity depends on frequency [30]. Frequency dependent fractional power law of AC conductivity has been explored variety of disordered materials, for example polymers, amorphous semiconductors along with conducting glasses [31]. Fractional power law (Eq. 1) was employing to observe the hopping of charge carriers (polarons and bipolarons) and also illustrate the $\mathrm{AC}$ conduction in conducting polymers [32-34]. AC conductivity enhances as frequency of applied field enhances in disorder polymers due to the hopping of charge carriers (polarons and bipolarons) moving small distance within the polymer chain. From Fig. 6, it is clear that $\sigma_{\mathrm{ac}}(\omega)$ increases with increase in frequency which can be due to restricted charges in high frequency region. Thus, fractional power law of AC conductivity was valuable tool to describe the hopping of charge carriers in conducting polymers [35].

\section{Conclusions}

The different weight percentage of $\mathrm{Y}_{2} \mathrm{O}_{3}$ nanoparticles based composites of PPy doped DBSA were successfully prepared by in situ polymerization technique. XRD and FTIR results exhibit the intercalation of conducting PPy-DBSA between nano- $\mathrm{Y}_{2} \mathrm{O}_{3}$ layers and thus, confirm the formation of PPy-DBSA- $\mathrm{Y}_{2} \mathrm{O}_{3}$ composites. The SEM also confirms the formation of dual phase of platelet as well as flakier structure in PPy-DBSA- $\mathrm{Y}_{2} \mathrm{O}_{3}$. AC conductivity $\left(\sigma_{\mathrm{ac}}\right)$, dielectric constant $\left(\varepsilon^{\prime}\right)$ and loss factor $\left(\varepsilon^{\prime \prime}\right)$ were enhanced with increased in $\mathrm{Y}_{2} \mathrm{O}_{3}$ content in PPy-DBSA composites may be suitable candidates for electronic devices applications.

Open Access This article is distributed under the terms of the Creative Commons Attribution 4.0 International License (http://creativecommons.org/licenses/by/4.0/), which permits unrestricted use, distribution, and reproduction in any medium, provided you give appropriate credit to the original author(s) and the source, provide a link to the Creative Commons license, and indicate if changes were made.

\section{References}

1. L.H. Sperling, Introduction to Physical Polymer Science (Wiley, Hoboken, 2005)

2. T.Z. Rizvi, A. Shakoor, Electrical conductivity and dielectric properties of polypyrrole/Na +- montmorillonite $(\mathrm{PPy} / \mathrm{Na}+-$ MMT) clay nanocomposites. J. Phys. D 42(9), 095415 (2009)

3. R.B. Kaner, A.G. MacDiarmid, Plastics that conduct electricity. Sci. Am. 258(2), 106-111 (1988)

4. M. Alexandre, P. Dubois, Polymer-layered silicate nanocomposites: preparation, properties and uses of a new class of materials. Mater. Sci. Eng. R 28(1-2), 1-63 (2000)

5. J. Li, L. Zhu, Y. Wu, Y. Harima, A. Zhang, H. Tang, Hybrid composites of conductive polyaniline and nanocrystalline titanium oxide prepared via self-assembling and graft polymerization. Polymer 47(21), 7361-7367 (2006)

6. I.H. Campbell, D.L. Smith, Physics of organic electronic devices. Solid State Phys. 55, 1-117 (2001)

7. M.S. Whittingham, Chemistry of intercalation compounds: metal guests in chalcogenide hosts. Prog. Solid State Chem. 12(1), 41-99 (1978)

8. R. Clement, M.L. Green, Organometallic intercalates of some lamellar metal phosphorus trisulphides. J. Chem. Soc. Dalton Trans. 10, 1566-1568 (1979)

9. T.K. Vıshnuvardhan, V.R. Kulkarnı, C. Basavaraja, S.C. Raghavendra, Synthesis, characterization and AC conductivity of polypyrrole/ $\mathrm{Y}_{2} \mathrm{O}_{3}$ composites. Bull. Mater. Sci. 29(1), 77-83 (2006)

10. Q. Cheng, V. Pavlinek, C. Li, A. Lengalova, Y. He, P. Saha, Synthesis and structural properties of polypyrrole/nano- $\mathrm{Y}_{2} \mathrm{O}_{3}$ conducting composite. Appl. Surf. Sci. 253(4), 1736-1740 (2006)

11. J.M. Frechet, D.A. Tomalia, Dendrimers and Other Dendritic Polymers, Wiley Series in Polymer Science (Wiley, Hoboken, 2001)

12. M. Thirumal, D. Khastgir, N.K. Singha, B.S. Manjunath, Y.P. Naik, Effect of a nanoclay on the mechanical, thermal and flame retardant properties of rigid polyurethane foam. J. Macromol. Sci. Part A 46(7), 704-712 (2009)

13. A. Kassim, H.E. Mahmud, F. Adzmi, Polypyrrole-montmorillonite clay composites: an organic semiconductor. Mater. Sci. Semicond. Process. 10(6), 246-251 (2007)

14. Q. Sun, F.J. Schork, Y. Deng, Water-based polymer/clay nanocomposite suspension for improving water and moisture barrier in coating. Compos. Sci. Technol. 67(9), 1823-1829 (2007)

15. A. Olad, A. Rashidzadeh, Preparation and anticorrosive properties of PANI/Na-MMT and PANI/O-MMT nanocomposites. Prog. Org. Coat. 62(3), 293-298 (2008)

16. M. Mravčáková, M. Omastová, P. Pötschke, A. Pozsgay, B. Pukánszky, J. Pionteck, Poly(propylene)/montmorillonite/polypyrrole 
composites: structure and conductivity. Polym. Adv. Technol. 17(9-10), 715-726 (2006)

17. W.S. Huang, B.D. Humphrey, A.G. MacDiarmid, POLYANILINE, A. N. C. P., Morphology and chemistry of its oxidation and reduction in aqueous electrolytes. J. Chem. Soc., Faraday Trans. 1(82), 2385 (1986)

18. R.F. Bianchi, M.F. Panssiera, J.P.H. Lima, L. Yagura, A.M.D. Andrade, R.M. Faria, Spin coater based on brushless de motor of hard disk drivers. Prog. Org. Coat. 57(1), 33-36 (2006)

19. G. Gustafsson, G.M. Treacy, Y. Cao, F. Klavetter, N. Colaneri, A.J. Heeger, The, "plastic" led: a flexible light-emitting device using a polyaniline transparent electrode. Synth. Met. 57(1), 4123-4127 (1993)

20. R.K. Choubey, D. Desai, S.N. Kale, S. Kumar, Effect of annealing treatment and deposition temperature on CdS thin films for CIGS solar cells applications. J. Mater. Sci. 27(8), 7890-7898 (2016)

21. A.L. Patterson, The Scherrer formula for X-ray particle size determination. Phys. Rev. 56(10), 978 (1939)

22. Khan, A. S. Preparation, characterization and studies of conducting polymer composites and blends (Doctoral dissertation, Quaidi-Azam University Islamabad, Pakistan) (2009)

23. W.L. Bragg, The diffraction of short electromagnetic waves by a crystal. Scientia 23(45), 153 (1929)

24. S. Abdul, Z.R. Tasneem, U.F. Hafiz, H. Najmul, M. Abdul, S. Muhammad, A comparative study of structural, thermal and electrical properties of undoped and doped with dodecylbenzenesulphonic acid polypyrrole. Высокомолекулярные соединения. Серия Б 53(10), 1833-1838 (2011)

25. S. Saravanan, C.J. Mathai, M.R. Anantharaman, S. Venkatachalam, P.V. Prabhakaran, Investigations on the electrical and structural properties of polyaniline doped with camphor sulphonic acid. J. Phys. Chem. Solids 67(7), 1496-1501 (2006)

26. B.R. Manjunath, A. Venkataraman, T. Stephen, The effect of moisture present in polymers on their X-ray diffraction patterns. J. Appl. Polym. Sci. 17(4), 1091-1099 (1973)
27. N. Arsalani, K.E. Geckeler, Novel electrically conducting polymer hybrids with polypyrrole. React. Funct. Polym. 33(2-3), 167-172 (1997)

28. K.S. Jang, H. Lee, B. Moon, Synthesis and characterization of water soluble polypyrrole doped with functional dopants. Synth. Met. 143(3), 289-294 (2004)

29. S. Lamprakopoulos, D. Yfantis, A. Yfantis, D. Schmeisser, J. Anastassopoulou, T. Theophanides, An FTIR study of the role of $\mathrm{H}_{2} \mathrm{O}$ and $\mathrm{D}_{2} \mathrm{O}$ in the aging mechanism of conductive polypyrroles. Synth. Met. 144(3), 229-234 (2004)

30. S. Yoshimoto, F. Ohashi, T. Kameyama, Simple preparation of sulfate anion-doped polyaniline-clay nanocomposites by an environmentally friendly mechanochemical synthesis route. Macromol. Rapid Commun. 25(19), 1687-1691 (2004)

31. A.K. Jonscher, Chelsea Dielectric Press (Google Scholar, London, 1983)

32. R. Singh, A.K. Narula, R.P. Tandon, A. Mansingh, S. Chandra, Low frequency alternating current conduction and dielectric relaxation in polypyrrole, poly(N-methyl pyrrole), and their copolymers. J. Appl. Phys. 80(2), 985-992 (1996)

33. P. Dutta, S. Biswas, S.K. De, Alternating-current conductivity and dielectric permittivity of polyaniline doped with $\beta$-naphthalene sulphonic acid. J. Phys. 13(41), 9187 (2001)

34. K.M. Jäger, D.H. McQueen, I.A. Tchmutin, N.G. Ryvkina, M. Klüppel, Electron transport and ac electrical properties of carbon black polymer composites. J. Phys. D 34(17), 2699 (2001)

35. A.K. Jonscher, The 'universal'dielectric response. Nature 267(5613), 673 (1977)

Publisher's Note Springer Nature remains neutral with regard to jurisdictional claims in published maps and institutional affiliations. 